\title{
Fatores de risco na transmissão e soroprevalência da infecção de Chlamydophila abortus a ovinos e caprinos
}

\author{
Tadeu Bezerra Leopoldo(1), Raymundo Rizaldo Pinheiro(2), Francisco Selmo Fernandes Alves ${ }^{(2)}$, \\ Kenney de Paiva Porfirio(1), Wagner Martins Fontes do Rêgo ${ }^{(1)}$, Bruno Leandro Maranhão Diniz ${ }^{(1)}$, \\ Janaina de Fátima Saraiva Cardoso(1) e Ney Rômulo de Oliveira Paula(1)
}

\begin{abstract}
(1)Universidade Federal do Piauí, Campus Universitário Ministro Petrônio Portella, Centro de Ciências Agrárias, Ininga, CEP 64049-550 Teresina, PI, Brasil. E-mail: tadeuleopoldo@hotmail.com, kenneymv@hotmail.com, wagner.fontesrego@gmail.com, brunoleandrodiniz@ufpi.edu.br, janainadefatima@ufpi.edu.br, neyromulo@ufpi.edu.br (2)Embrapa Caprinos e Ovinos, Fazenda Três Lagoas, Estrada Sobral, Km 04, s/no, CEP 62010-970 Sobral, CE, Brasil. E-mail: rizaldo.pinheiro@embrapa.br, selmo.alves@embrapa.br
\end{abstract}

Resumo - O objetivo deste trabalho foi avaliar os fatores de risco envolvidos na transmissão de Chlamydophila abortus a ovinos e caprinos, bem como verificar a soroprevalência da infecção. Foram selecionadas 110 propriedades, com um total de 500 amostras de ovinos - 350 da Microrregião do Alto Médio Gurgueia (MRAMG) e 150 da Microrregião Homogênea de Teresina (MRHT), ambas do Estado do Piauí - e 600 amostras de caprinos - 300 da MRAMG e 300 da MRHT. Um questionário epidemiológico foi empregado para identificar os principais fatores de risco. Os anticorpos anti-C. abortus foram detectados pela técnica de fixação de complemento. A prevalência geral da infecção por C. abortus foi de 7,2\% (79/1.100). A prevalência em caprinos e ovinos na MRAMG foi de 7,9\% (51/650) e, na MRHT, foi de 6,2\% (28/450). Nas microrregiões estudadas, a prevalência em ovinos foi de 8,2\% (41/500) e, em caprinos, de 6,3\% (38/600). O sistema de criação, as práticas reprodutivas e o tipo racial foram fatores de risco relevantes para a infecção em ovinos. Também foram relevantes em caprinos as práticas reprodutivas e a origem das matrizes e dos reprodutores. A raça Dorper apresenta maior suscetibilidade à infecção por $C$. abortus.

Termos para indexação: Capra aegagrus hircus, Ovis aries, clamidofilose, epidemiologia, manejo reprodutivo, pequenos ruminantes.

\section{Risk factors in the transmission and seroprevalence of Chlamydophila abortus infection in sheep and goats}

\begin{abstract}
The objective of this work was to evaluate the risk factors involved in the transmission of Chlamydophila abortus to sheep and goats, as well as to verify the seroprevalence of the infection. One hundred ten farms were selected, with a total of 500 sheep samples - 350 from the Microregion of Alto Médio Gurgueia (MRAMG), and 150 from the Homogeneous Microregion of Teresina (MRHT), both in the state of Piauí, Brazil - and 600 goat samples - 300 of the MRAMG and 300 of the MRHT. An epidemiological questionnaire was used to identify the main risk factors. Anti-C. abortus antibodies were detected by the complement fixation technique. Overall prevalence of infection by $C$. abortus was $7.2 \%(79 / 1,100)$. The prevalence in goats and sheep in the MRAMG was 7.9\% (51/650), and in the MRHT it was $6.2 \%(28 / 450)$. In the studied microregions, the prevalence in sheep was $8.2 \%(41 / 500)$, and in goats it was $6.3 \%(38 / 600)$. The raising system, reproductive practices, and racial type were significant risk factors for infection in sheep. Also significant in goats were the reproductive practices and the origin of the does and bucks. The Dorper breed shows increased susceptibility to infection with C. abortus.
\end{abstract}

Index terms: Capra aegagrus hircus, Ovis aries, chlamydofilosis, epidemiology, reproductive management, small ruminant.

\section{Introdução}

Adoença clamidofilose é causada por Chlamydophila abortus, bactéria intracelular obrigatória, Gramnegativa e conhecida como "parasita de energia" (Quinn et al., 2011). O ciclo das Chlamydiae consiste de duas formas: a infecção por corpos elementares, que são relativamente estáveis no meio ambiente, e por corpo reticular vegetativo, que se desenvolve a partir do estágio anterior, no citoplasma da célula do hospedeiro (Longbottom \& Coulter, 2003).

Esta bactéria é um agente patogênico zoonótico que infecta animais de criação e que tem sido apontado como importante causa de abortos em caprinos e 
ovinos (Ababneh et al., 2014). Em ovinos, o agente causa o aborto enzoótico, que é caracterizado por aborto no final da gestação ou por nascimento de cordeiros prematuros e fracos (Marsilio et al., 2005). Além disso, C. abortus induz abortos em humanos e doença sistêmica semelhante à gripe, como resultado do contato direto com fluidos e material abortado por ovelhas e cabras soropositivas (Pospischil et al., 2002; Stone et al., 2012).

As doenças infecciosas reprodutivas são classificadas como entraves à ovinocaprinocultura mundial e têm como consequências principais as perdas embrionárias e fetais. Os agentes normalmente descritos neste tocante são a Brucella sp. (Samadi et al., 2010; Wareth et al., 2015), Chlamydophila sp. (Pereira et al., 2009; Hazlett et al., 2013), Leptospira sp. (Cortizo et al., 2015), Toxoplasma gondii (Chessa et al., 2014) e Neospora caninum (Anderlini et al., 2011). Em países da Europa, América do Norte, África e Ásia, onde a bactéria $C$. abortus é endêmica, ocorrem perdas econômicas significativas (Longbottom \& Coulter, 2003; Chisu et al., 2013).

A importância da clamidofilose é expressiva tanto no Brasil como em outros países, principalmente ao considerarmos o Brasil como importador e exportador de material genético. De acordo com Rossi et al. (2012) o impacto econômico da clamidofilose em rebanhos ovinos está relacionado, principalmente, a maiores taxas de aborto e menores taxas de sobrevivência de cordeiros.

A ovinocaprinocultura no Estado do Piauí é caracterizada por diversas falhas de manejo, principalmente por falta de assistência técnica especializada. Diversas enfermidades são relatadas, pelos produtores, como responsáveis pela ocorrência de perdas produtivas mas ainda sem diagnóstico oficial (Silva et al., 2011). Em termos específicos, o teste da reação de fixação de complemento pode detectar anticorpos advindos de infecção natural ou aqueles produzidos em pós-vacinação (World Organisation for Animal Health, 2012). De acordo com relatos dos produtores, os animais da microrregião do Alto Médio Gurgueia e da Microrregião Homogênea de Teresina, normalmente, não são vacinados contra $C$. abortus. Assim, consideram-se relevantes: a realização de uma investigação sobre a prevalência da C. abortus em caprinos e ovinos; e conhecer os principais fatores de risco, envolvidos na transmissão desta bactéria.
O objetivo deste trabalho foi avaliar os fatores de risco envolvidos na transmissão da Chlamydophila abortus a ovinos e caprinos e verificar a soroprevalência da infecção.

\section{Material e Métodos}

A área de atuação deste estudo compreendeu duas microrregiões do Estado do Piauí, descritas a seguir. A Microrregião do Alto Médio Gurgueia (MRAMG) localiza-se no sudoeste do Estado, abrange 11 municípios, em $27.609,0 \mathrm{~km}^{2}$ de área territorial, entre $08^{\circ} 25^{\prime} 28^{\prime \prime} \mathrm{S}$ e $09^{\circ} 55^{\prime} 31^{\prime \prime S} 43^{\circ} 46^{\prime} 38^{\prime \prime} \mathrm{W}$ e $45^{\circ} 28^{\prime} 30^{\prime \prime} \mathrm{W}$. Apresenta média de temperatura mínima de $25^{\circ} \mathrm{C}$ e máxima de $36^{\circ} \mathrm{C}$, com clima quente e semiúmido, cobertura vegetal que varia entre cerrado e caatinga, e período chuvoso de novembro a abril (Instituto Brasileiro de Geografia e Estatística, 2012). A Microrregião Homogênea de Teresina (MRHT) situa-se na Mesorregião Centro-Norte, entre $4^{\circ} 30^{\prime} 566^{\prime \prime} \mathrm{N}$ e $5^{\circ} 35^{\prime} 0^{\prime \prime} \mathrm{N}$ e $42^{\circ} 46^{\prime} 40^{\prime \prime} \mathrm{W}$ e $42^{\circ} 12^{\prime} 12^{\prime \prime} \mathrm{W}$, com quatorze municípios que juntos compõem uma área territorial de $9.213,120 \mathrm{~km}^{2}$ (Instituto Brasileiro de Geografia e Estatística, 2012).

Amostras do banco de soro da Embrapa Caprinos e Ovinos foram utilizadas, assim como informações das propriedades de origem depositadas no banco de dados da Embrapa. As amostras foram coletadas de janeiro a junho de 2012 e analisadas de agosto a setembro de 2012.

Foram analisadas 1.100 amostras de soro sanguíneo, oriundas de 50 rebanhos de ovinos (35 da MRAMG e 15 da MRHT) e 60 rebanhos de caprinos (30 da MRAMG e 30 da MRHT), que totalizaram 500 amostras de ovinos (350 da MRAMG e 150 da MRHT) e 600 de caprinos (300 da MRAMG e 300 da MRHT). Além das coletas de soro, também se aplicou um questionário epidemiológico a cada propriedade, para conhecer as principais variáveis envolvidas na prevalência da C. abortus, com perguntas sobre o sistema de criação adotado, características gerais da propriedade, tamanho do rebanho, tipo de produção, origem dos animais e práticas reprodutivas empregadas, entre outras informações sobre os manejos reprodutivo, sanitário e nutricional adotados para a criação de ovinos e caprinos.

No banco de soro, cada propriedade identificada compôs um lote, num total de 110 lotes. Cada lote continha 20 amostras armazenadas a $-20^{\circ} \mathrm{C}$, entre as 
quais 10 amostras foram selecionadas aleatoriamente. Para avaliação de anticorpos anti-Chlamydophila sp., empregou-se a microtécnica de fixação de complemento (World Organisation for Animal Health, 2012), realizada no Laboratório de Doenças Bacterianas da Reprodução, do Instituto Biológico de São Paulo, SP. A reação foi realizada em microplacas, com a utilização de soro-teste em diluições de 1:16 a 1:512. Utilizou-se como antígeno a cepa S26/3 de C. abortus, na diluição 1:50, e o complemento na diluição correspondente a duas unidades fixadoras de complemento. O título de anticorpos foi considerado como a recíproca da maior diluição de soro que apresentou $50 \%$ de fixação do complemento.

Consideraram-se positivos para a infecção por C. abortus aqueles animais que apresentaram título de anticorpos acima de 1:32, pois, títulos inferiores em pequenos ruminantes são considerados inespecíficos para C. abortus (World Organisation for Animal Health, 2012).

A análise estatística foi realizada com base no desenho amostral por conglomerados. A associação entre a ocorrência da infecção e os fatores de risco foi realizada pela análise não paramétrica, tendo-se utilizado o teste de qui-quadrado $\left(\chi^{2}\right)$. Após a análise dos dados, calculou-se a prevalência, bem como sua associação com os fatores de risco avaliados, tendo-se considerado o intervalo de confiança de $95 \%$, por meio do teste exato de Fisher.

\section{Resultados e Discussão}

Observa-se que C. abortus esteve presente em MRAMG e em MRHT, contudo, não houve diferença quanto à infecção em ovinos e caprinos entre as microrregiões (Tabela 1). Também não se observou diferença quanto à infecção entre ovinos e caprinos.

Em geral, os títulos observados foram baixos, e o maior foi de 64. Ressalta-se que a reação cruzada entre $C$. abortus e C. pecorum, assim como com outras bactérias Gram-negativas, pode resultar em alguns resultados falso-positivos com baixos títulos (Donn et al., 1997; Pereira et al., 2009). O alto número de animais suspeitos em comparação ao número de animais positivos, no presente trabalho, pode significar um número bem maior de animais positivos (Pereira et al., 2009). Como não se realizou a sorologia pareada nessas amostras, não foi possível confirmar este diagnóstico.
Os fatores sexo, tamanho do rebanho, tipo de produção, origem das matrizes e origem dos reprodutores não apresentaram associação com a soropositividade da infecção em rebanhos de ovinos (Tabela 2). No entanto, os fatores sistema de criação, prática reprodutiva adotada e raça registraram associação com a soropositividade à infecção por C. abortus. $N a$ avaliação dos fatores de risco para a infecção por C. abortus, em rebanhos caprinos, a prática reprodutiva adotada, origem das matrizes e origem dos reprodutores apresentaram associação com a soropositividade à infecção (Tabela 3). Contudo, a mesma associação não pôde ser observada nos fatores sexo, sistema de criação, tamanho do rebanho, tipo de produção e raça, pois não apresentaram associação com a infecção nos rebanhos de caprinos.

A prevalência geral de 7,2\% (79/1100) da infecção por C. abortus em caprinos e ovinos, no Estado do Piauí, foi inferior à encontrada no Estado de Pernambuco, de 10,3\% (Pereira et al., 2009). A prevalência de ovinos oriundos da MRAMG e da MRHT soropositivos a C. abortus foi de 8,2\% (41/500), valor inferior ao relatado por Rossi et al. (2012), sobre animais nos estados de São Paulo e Minas Gerais, e por Pinheiro Junior et al. (2010), no estado de Alagoas. Pereira et al. (2009) encontraram prevalência de $8,1 \%$ para o estado de Pernambuco.

A prevalência de caprinos soropositivos foi de $6,3 \%$ $(38 / 600)$. No Brasil, frequência inferior foi encontrada no Estado da Paraíba, por Santos et al. (2012). Valores semelhantes foram relatados para os estados de Pernambuco, São Paulo, Minas Gerais, Mato Grosso e Bahia (Piatti et al., 2006; Pereira et al., 2009).

Tabela 1. Percentagem da prevalência da infecção por Chlamydophila abortus em rebanhos caprinos e ovinos, pelo teste de fixação de complemento, na Microrregião do Alto Médio Gurgueia (MRAMG) e Microrregião Homogênea de Teresina (MRHT), no Estado do Piauí, Brasil, 2012.

\begin{tabular}{lccccc}
\hline Espécie & \multirow{2}{*}{ Microrregião } & Suspeito & \multicolumn{2}{c}{ Positivo } & \multirow{2}{*}{ Negativo } \\
\cline { 4 - 5 } & & $1: 16$ & $1: 32$ & $1: 64$ & \\
\hline \multirow{2}{*}{ Ovina } & MRAMG & $4,0(14)$ & $7,4(26) \mathrm{a}$ & $1,1(4) \mathrm{a}$ & $87,4(306)$ \\
& MRHT & $4,0(6)$ & $6,7(10) \mathrm{a}$ & $0,7(1) \mathrm{a}$ & $88,7(133)$ \\
\hline \multirow{2}{*}{ Caprina } & MRAMG & $5,7(17)$ & $6,7(20) \mathrm{a}$ & $0,3(1) \mathrm{a}$ & $87,3(262)$ \\
& MRHT & $4,7(14)$ & $5,3(16) \mathrm{a}$ & $0,3(1) \mathrm{a}$ & $89,7(269)$ \\
\hline
\end{tabular}

(1)Médias seguidas de letras iguais, entre regiões e mesma espécie, não diferem pelo teste exato de Fisher, a 5\% de probabilidade. O valor entre parênteses refere-se ao número de animais. 
Valores de prevalência superiores aos encontrados no presente trabalho, já foram reportados mundialmente, como: Estados Unidos, com 23\% em caprinos Moeller (2001); Jordânia, com 21,8\% em pequenos ruminantes (Al-Qudah et al., 2004); Turquia, com 13,98\% em ovinos (Gokce et al., 2007); Lituânia, com 26,9\% em ovinos (Bagdonas et al., 2007); e China, com 20,9\%. em ovinos (Huang et al., 2013). A soroprevalência da infecção por C. abortus, em ovinos submetidos ao sistema semi-intensivo de criação, foi superior à encontrada em rebanhos ovinos criados extensivamente (Tabela 2). Pereira et al. (2009) e Santos et al. (2012) analisaram o fator de risco sistema de criação, em rebanhos caprinos e ovinos, nos estados da Paraíba e Pernambuco, e também observaram soroprevalência superior em animais criados no sistema intensivo ou semi-intensivo. Isto mostra a importância do contato e da aglomeração na transmissão da clamidofilose.

Nas práticas reprodutivas adotadas em propriedades produtoras de ovinos, a monta natural controlada mostrou associação significativa quanto à infecção por C. abortus, em comparação aos animais submetidos à monta natural não controlada. Isto mostra que o manejo reprodutivo é importante na transmissão venérea, uma vez que há eliminação do agente em excreções vaginais e fluído seminal de carneiros (Pereira et al., 2009). A Clamydophila já foi isolada do fluído seminal de carneiros (Bernstein \& Yaakobovitz, 1990), touros (Gomes et al., 2001) e varrões (Teankum et al., 2006). No presente estudo, a prevalência de reprodutores

Tabela 2. Fatores de risco, associados à infecção por Chlamydophila abortus em rebanhos ovinos, pelo teste de fixação de complemento, na Microrregião do Alto Médio Gurgueia e Microrregião Homogênea de Teresina, no Estado do Piauí, Brasil, 2012.

\begin{tabular}{|c|c|c|c|}
\hline \multirow[t]{2}{*}{ Fator de risco } & \multicolumn{3}{|c|}{ Prevalência da Chlamydophila abortus $(\%)$} \\
\hline & Positivo & Suspeito & Negativo \\
\hline \multicolumn{4}{|l|}{ Sexo } \\
\hline Fêmea & $7,9(35 / 445) \mathrm{a}$ & $4,0(18 / 445)$ & $88,1(392 / 445)$ \\
\hline Macho & $10,5(6 / 57) \mathrm{a}$ & $3,5(2 / 57)$ & $86,0(49 / 57)$ \\
\hline \multicolumn{4}{|l|}{ Sistema de criação } \\
\hline Extensivo & $7,5(23 / 306) \mathrm{a}$ & $3,6(11 / 306)$ & $88,9(272 / 306)$ \\
\hline Semi-intensivo & $17,7(11 / 62) b$ & $3,2(2 / 62)$ & $79,0(49 / 62)$ \\
\hline \multicolumn{4}{|l|}{ Tamanho do rebanho } \\
\hline Grande & $10,4(22 / 212) \mathrm{a}$ & $4,2(9 / 212)$ & $85,4(181 / 212)$ \\
\hline Pequeno & $6,8(10 / 146) \mathrm{a}$ & $2,7(4 / 146)$ & $90,4(132 / 146)$ \\
\hline \multicolumn{4}{|l|}{ Tipo de produção } \\
\hline Carne & $8,9(31 / 348) \mathrm{a}$ & $3,7(13 / 348)$ & $87,4(304 / 348)$ \\
\hline Misto & $10,0(1 / 10) \mathrm{a}$ & $0,0(0 / 10)$ & $90,0(9 / 10)$ \\
\hline \multicolumn{4}{|l|}{ Práticas reprodutivas adotadas } \\
\hline Monta natural não controlada & $8,7(31 / 356) \mathrm{a}$ & $3,4(12 / 356)$ & $87,9(313 / 356)$ \\
\hline Monta natural controlada & $25,0(3 / 12) b$ & $8,3(1 / 12)$ & $66,7(8 / 12)$ \\
\hline \multicolumn{4}{|l|}{ Origem das matrizes } \\
\hline Do próprio rebanho & $8,3(13 / 156) \mathrm{a}$ & $5,8(9 / 156)$ & $85,9(134 / 156)$ \\
\hline Feiras (rebanhos desconhecidos) & $13,6(3 / 22) \mathrm{a}$ & $0,0(0 / 22)$ & $86,4(19 / 22)$ \\
\hline Rebanhos conhecidos ou vizinhos & $8,9(8 / 90) \mathrm{a}$ & $3,3(3 / 90)$ & $87,8(79 / 90)$ \\
\hline Duas opções ou mais & $10,0(8 / 80) \mathrm{a}$ & $1,3(1 / 80)$ & $88,8(71 / 80)$ \\
\hline \multicolumn{4}{|l|}{ Origem dos reprodutores } \\
\hline Compra em exposição & $16,7(7 / 42) \mathrm{a}$ & $7,1(3 / 42)$ & $76,2(32 / 42)$ \\
\hline Feiras (rebanhos desconhecidos) & $0,0(0 / 16)$ & $0,0(0 / 16)$ & $100,0(16 / 16)$ \\
\hline Rebanhos conhecidos ou vizinhos & $8,6(18 / 210) \mathrm{a}$ & $1,9(4 / 210)$ & $89,5(188 / 210)$ \\
\hline Duas opções ou mais & $10,0(7 / 70) a$ & $4,3(3 / 70)$ & $85,7(60 / 70)$ \\
\hline Outro & $0,0(0 / 80)$ & $0,0(0 / 80)$ & $100,0(80 / 80)$ \\
\hline \multicolumn{4}{|l|}{ Raça } \\
\hline Dorper & $20,0(1 / 05) \mathrm{a}$ & $0,0(0 / 05)$ & $80,0(4 / 05)$ \\
\hline Santa Inês & $8,7(17 / 196)$ & $4,6(9 / 196)$ & $86,7(170 / 196)$ \\
\hline Sem raça definida & $7,6(23 / 301) b$ & $3,7(11 / 301)$ & $88,7(267 / 301)$ \\
\hline
\end{tabular}

${ }^{(1)}$ Médias seguidas de letras iguais, nas colunas, não diferem pelo teste exato de Fisher, a $5 \%$ de probabilidade. Valores entre parênteses referem-se ao número de animais sobre o total de animais avaliados. 
caprinos e ovinos soropositivos foi baixa, no entanto, a possibilidade de ocorrência da transmissão venérea não pode ser descartada, pois os animais pesquisados poderiam estar com títulos baixos de anticorpos e, mesmo assim, com liberação da bactéria via sêmen. Assim como as práticas reprodutivas, a origem das matrizes e reprodutores mostrou ser um importante fator de risco para a enfermidade, tendo-se em vista que a aquisição de animais destinados à reprodução, oriundos de rebanhos vizinhos e sobretudo sem controle sanitário, pode contribuir para a disseminação da enfermidade na região estudada.

Os ovinos da raça Dorper apresentaram maior incidência de infecção pela $C$. abortus, com maior prevalência do os da raça Santa Inês e aqueles sem raça definida (SRD). Nos rebanhos caprinos, apenas os animais SRD apresentaram soropositividade à infecção pelo agente pesquisado, possivelmente, pelo fato de estes animais perfazerem a maior parte da população analisada, aliado ao fato de os criadores apresentarem mais cuidado no manejo sanitário dos animais que possuem padrão racial definido, em virtude de seu maior valor comercial.

Encontrou-se um baixo número de animais com títulos reduzidos de anticorpos $(\leq 1: 16)$ anti-C. abortus (Tabela 1), o que pode significar animais com títulos ainda crescentes (falso-negativo) ou animais com reação cruzada. Neste caso, testes sorológicos pareados

Tabela 3. Fatores de risco, associados à infecção por Chlamydophila abortus em rebanhos caprinos, pelo teste de fixação de complemento, na Microrregião do Alto Médio Gurgueia e Microrregião Homogênea de Teresina, no Estado do Piauí, Brasil, $2012^{(1)}$.

\begin{tabular}{|c|c|c|c|}
\hline \multirow[t]{2}{*}{ Fator de risco } & \multicolumn{3}{|c|}{ Prevalência da Chlamydophila abortus $(\%)$} \\
\hline & Positivo & Suspeito & Negativo \\
\hline \multicolumn{4}{|l|}{ Sexo } \\
\hline Fêmea & $6,4(35 / 551) \mathrm{a}$ & $4,5(25 / 551)$ & $89,1(491 / 551)$ \\
\hline Macho & $6,4(3 / 47) \mathrm{a}$ & $12,8(6 / 47)$ & $80,9(38 / 47)$ \\
\hline \multicolumn{4}{|l|}{ Sistema de criação } \\
\hline Extensivo & $7,5(21 / 280) \mathrm{a}$ & $6,1(17 / 280)$ & $86,4(242 / 280)$ \\
\hline Semi-intensivo & $7,9(3 / 38) \mathrm{a}$ & $7,9(03 / 38)$ & $84,2(32 / 38)$ \\
\hline \multicolumn{4}{|l|}{ Tamanho do rebanho } \\
\hline Grande & $8,9(17 / 190) \mathrm{a}$ & $6,3(12 / 190)$ & $84,7(161 / 190)$ \\
\hline Pequeno & $5,5(7 / 128) \mathrm{a}$ & $6,3(8 / 128)$ & $88,3(113 / 128)$ \\
\hline \multicolumn{4}{|l|}{ Tipo de produção } \\
\hline Carne & $7,5(23 / 308) a$ & $5,8(18 / 308)$ & $86,7(267 / 308)$ \\
\hline Misto & $10,0(1 / 10) \mathrm{a}$ & $20,0(2 / 10)$ & $70,0(7 / 10)$ \\
\hline \multicolumn{4}{|l|}{ Práticas reprodutivas adotadas } \\
\hline Monta natural não controlada & $7,6(22 / 290) \mathrm{a}$ & $6,2(18 / 290)$ & $86,2(250 / 290)$ \\
\hline Monta natural controlada & $0,0(0 / 18)$ & $0,0(0 / 18)$ & $100,0(18 / 18)$ \\
\hline Práticas combinadas & $20,0(2 / 10) \mathrm{b}$ & $20,0(2 / 10)$ & $60,0(6 / 10)$ \\
\hline \multicolumn{4}{|l|}{ Origem das matrizes } \\
\hline Próprio rebanho & $4,4(7 / 160) a$ & $8,1(13 / 160)$ & $87,5(140 / 160)$ \\
\hline Feiras (rebanhos desconhecidos) & $5,6(1 / 18) \mathrm{a}$ & $0,0(0 / 18)$ & $94,4(17 / 18)$ \\
\hline Rebanhos conhecidos ou vizinhos & $13,3(8 / 60) \mathrm{b}$ & $3,3(2 / 60)$ & $83,3(50 / 60)$ \\
\hline Duas opções ou mais & $8,6(6 / 70) \mathrm{ab}$ & $5,7(4 / 70)$ & $85,7(60 / 70)$ \\
\hline \multicolumn{4}{|l|}{ Origem do Reprodutores } \\
\hline Compra em exposição & $0,0(0 / 18)$ & $0,0(0 / 18)$ & $100,0(18 / 18)$ \\
\hline Feiras (rebanhos desconhecidos) & $20,0(2 / 10) \mathrm{a}$ & $20,0(2 / 10)$ & $60,0(6 / 10)$ \\
\hline Rebanhos conhecidos ou vizinhos & $7,1(15 / 210) b$ & $5,2(11 / 210)$ & $87,6(184 / 210)$ \\
\hline Duas opções ou mais & $10,0(7 / 70) \mathrm{ab}$ & $8,6(6 / 70)$ & $81,4(57 / 70)$ \\
\hline \multicolumn{4}{|l|}{ Raça } \\
\hline Anglo-Nubiano & $0,0(0 / 55)$ & $0,0(0 / 55)$ & $100,0(55 / 55)$ \\
\hline Boer & $0,0(0 / 11)$ & $0,0(0 / 11)$ & $100,0(11 / 11)$ \\
\hline Nambi & $0,0(0 / 01)$ & $100,0(1 / 01)$ & $0,0(0 / 1)$ \\
\hline Sem raça definida & $7,2(38 / 531)$ & $5,6(30 / 531)$ & $87,2(463 / 531)$ \\
\hline
\end{tabular}

${ }^{(1)}$ Médias seguidas de letras iguais, nas colunas, para o mesmo fator de risco, diferem pelo teste exato de Fisher, a 5\% de probabilidade. Valores entre parênteses referem-se ao número de animais sobre o total de animais avaliados. 
poderiam esclarecer este diagnostico. Ressaltase que a permanência de animais falso-positivos no rebanho pode levar a dificuldades no controle e erradicação desta enfermidade. Em geral, os resultados encontrados mostram a realidade sanitária de rebanhos caprinos e ovinos, no Estado do Piauí, e registram a primeira ocorrência da infecção por Chlamydophila abortus em criações de caprinos e ovinos explorados neste Estado.

\section{Conclusões}

1. O agente infeccioso Chlamydophila abortus está presente em rebanhos ovinos e caprinos, na Microrregião do Alto Médio Gurgueia e na Microrregião Homogênea de Teresina, no Estado do Piauí.

2. O sistema de criação, práticas reprodutivas e tipo racial são fatores de risco relevantes para a infecção por C. abortus em rebanhos de ovinos.

3. As práticas reprodutivas e a origem das matrizes e reprodutores são fatores de risco relevantes para a infecção por C. abortus em rebanhos de caprinos.

\section{Agradecimentos}

Ao Conselho Nacional de Desenvolvimento Científico e Tecnológico (CNPq, processo 578438/2008-9), pelo financiamento da pesquisa.

\section{Referências}

ABABNEH, H.S.; ABABNEH, M.M.K.; HANANEH, W.M.; ALSHEYAB, F.M.; JAWASREH, K.I.; AL-GHARAIBEH, M.A.; ABABNEH, M.M. Molecular identification of chlamydial cause of abortion in small ruminants in Jordan. Tropical Animal Health Production, v.46, p.1407-1412, 2014. DOI: 10.1007/ s11250-014-0654-X.

AL-QUDAH, K.M.; SHARIF, L.A.; RAOUF, R.Y.; HAILAT, N.Q.; AL-DOMY, F.M. Seroprevalence of antibodies to Chlamydophila abortus shown in Awassi sheep and local goats in Jordan. Veterinární Medicína - Czech, v.49, p.460-466, 2004.

ANDERLINI, G.A.; FARIAS, E.B.; SILVA, A.M. da; PINHEIRO JÚNIOR, J.W.; VALENÇA, R.M.B.; ANDERLINI, G.P. de O. e S.; MOTA, R.A. Prevalência de anticorpos anti-Neospora caninum em caprinos no Estado de Alagoas, Brasil. Veterinária e Zootecnia, v.18, p.583-590, 2011.

BAGDONAS, J.; PETKEVICIUS, S.; RUSSO, P.; PEPIN, M.; SALOMSKAS, A. Prevalence and epidemiological features of ovine enzootic abortion in Lithuania. Polish Journal of Veterinary Sciences, v.10, p.239-244, 2007.
BERNSTEIN, M.D.; YAAKOBOVITZ, J. The identification and preventions of venereal transmission of Chlamydia psittaci in sheep. Israel. Journal of Veterinary Medicine, v.45, p.192, 1990.

CHESSA, G.; CHISU, V.; PORCU, R.; MASALA, G. Molecular characterization of Toxoplasma gondii type II in sheep abortion in Sardinia, Italy. Parasite, v.21, p.6, 2014. DOI: 10.1051/ parasite/2014007.

CHISU, V.; PORCU, R.; TANDA, A.; MASALA, G. First isolation and characterization of Chlamydophila abortus from abortion tissues of sheep in Sardinia, Italy. Veterinaria Italiana, v.49, p.331-334, 2013. DOI: 10.12834/VetIt.1303.10.

CORTIZO, P.; LOUREIRO, A.P.; MARTINS, G.; RODRIGUES, P.R. do; FARIA, B.P.; LILENBAUM, W.; DEMINICIS, B.B. Risk factors to incidental leptospirosis and its role on the reproduction of ewes and goats of Espírito Santo state, Brazil. Tropical Animal Health Production, v.47, p.231-235, 2015. DOI: 10.1007/ s11250-014-0684-4.

DONN, A.; CARNICLETTO, P.; CHIARACANE, G.; STANCANELLI, L. Standardizzazione della tecnica di fissazione del complemento per la dimostrazione di anticorpi anti-Chlamydia nel siero di sangue. Progresso Veterinario, v.4, p.125-128, 1997.

GOKCE, H.I.; KACAR, C.; GENC, O.; SOZMEN, M. Seroprevalance of Chlamydophila abortus in aborting ewes and dairy cattle in the North-East part of Turkey. Bulletin of the Veterinary Institute in Pulawy, v.51, p.9-13, 2007.

GOMES, M.J.P.O.; WALD, V.B.O.; MACHADO, R.D.O.; SILVEIRA, M.C. Isolamento de Chlamydia psittaci em touros com vesiculite seminal, no Rio Grande do Sul. A Hora Veterinária, v.119, p.43-46, 2001.

HAZLETT, M.J.; MCDOWALL, R.; DELAY, J.; STALKER, M.; McEWEN, B.; DREUMEL, T. van; SPINATO, M.; BINNINGTON, B.; SLAVIC, D.; CARMAN, S.; CAI, H.Y. A prospective study of sheep and goat abortion using real-time polymerase chain reaction and CUT point estimation shows Coxiella burnettii and Chlamydophila abortus infection concurrently with other major pathogens. Journal of Veterinary Diagnostic Investigation, v.25, p.359-368, 2013. DOI: 10.1177/1040638713484729.

HUANG, S.Y.; WU, S.M.; XU, M.J.; ZHOU, D.H.; DANBA, C.; GONG, G.; ZHU, X.-Q. First record of Chlamydia abortus seroprevalence in Tibetan sheep in Tibet, China. Small Ruminant Research, v.112, p.243-245, 2013. DOI: 10.1016/j. smallrumres.2012.12.012.

INSTITUTO BRASILEIRO DE GEOGRAFIA E ESTATÍSTICA. Produção da pecuária municipal 2012. 2012. Disponível em: $\quad<$ http://www.sidra.ibge.gov.br/bda/tabela/listabl. asp?c $=73 \& z=p \& o=21>$. Acesso em: 28 out. 2015.

LONGBOTTOM, D.; COULTER, L.J. Animal chlamydioses and zoonotic implications. Journal of Comparative Pathology, v.128, p.217-244, 2003. DOI: 10.1053/jcpa.2002.0629.

MARSILIO, F.; DI MARTINO, B.; DI FRANCESCO, C.E.; MERIDIANI, I. Diagnosis of ovine chlamydial abortions by PCR-RFLP performed on vaginal swabs. Veterinary Research Communications, v.29, p.99-106, 2005. DOI: 10.1007/ s11259-005-0840-4.

Pesq. agropec. bras., Brasília, v.51, n.5, p.654-660, maio 2016 DOI: $10.1590 / \mathrm{S} 0100-204 \mathrm{X} 2016000500028$ 
MOELLER JR, R.B. Causes of caprine abortion: diagnostic assessment of 11 cases (1991-1998). Journal of Veterinary Diagnostic Investigation, v.13, p.265-270, 2001. DOI: 10.1177/104063870101300317.

WORLD ORGANISATION FOR ANIMAL HEALTH. Enzootic abortion of ewes (ovine chlamydiosis). 2012. Available at: $<$ http:// www.oie.int/fileadmin/Home/fr/Health_standards/tahm/2.07.07 ENZ_ABOR.pdf $>$. Accessed on: 11 Oct. 2006.

PEREIRA, M. de F.; PEIXOTO, R. de M.; PIATTI, R.M.; MEDEIROS, E.S. de; MOTA, I.O. de; AZEVEDO, S.S. de; MOTA, R.A. Ocorrência e fatores de risco para Chlamydophila abortus em ovinos e caprinos no Estado de Pernambuco. Pesquisa Veterinária Brasileira, v.29, p.33-40, 2009. DOI: 10.1590/ S0100-736X2009000100005.

PIATTI, R.M.; SCARCELLI, E.P.; GENOVEZ, M.E. Pesquisa de anticorpos anti-Chlamydophila em caprinos e ovinos. O Biológico, v.68, p.138-140, 2006.

PINHEIRO JUNIOR, J.W.; MOTA, R.A.; PIATTI, R.M.; OLIVEIRA, A.A. da F.; SILVA, A.M. da; ABREU, S.R. de O.; ANDELINI, G.A.; VALENÇA, R.M.B. Seroprevalence of antibodies to Chamydophila abortus in ovine in the state of Alagoas, Brazil. Brazilian Journal of Microbiology, v.41, p.358-364, 2010. DOI: 10.1590/S1517-83822010000200015.

POSPISCHIL, A.; THOMA, R.; HILBE, M.; GREST, P.; GEBBERS, J.O. Abortion in woman caused by caprine Chlamydophila abortus (Chlamydia psittaci serovar 1). Swiss Medical Weekly, v.132, p.64-66, 2002.

QUINN, P.J.; MARKEY, B.K.; LEONARD, F.C.; FITZPATRICK, E.S.; FANNING, S.; HARTIGAN, P. Veterinary microbiology and microbial disease. $2^{\text {nd }}$ ed. West Sussex: Wiley-Blackwell, 2011. p.384-393.

ROSSI, R.S.; RIZZO, H.; PIATTI, R.M.; GREGORY, L. Sinais clínicos e ocorrência de anticorpos anti-Chlamydophila abortus em ovinos de São Paulo e Minas Gerais. Ciência Rural, v.42, p.2018-2024, 2012. DOI: 10.1590/S0103-84782012005000096.

SAMADI, A.; ABABNEH, M.M.K.; GIADINIS, N.D.; LAFI, S.Q. Ovine and caprine brucellosis (Brucella melitensis) in aborted animals in Jordanian sheep and goat flocks. Veterinary Medicine International, v.2010, 2010. DOI: 10.4061/2010/458695.

SANTOS, C.S.A.B.; PIATTI, R.M.; AZEVEDO, S.S.; ALVES, C.J.; HIGINO, S.S.S.; SILVA, M.L.C.R.; BRASIL, A.W.L.; GENNARI, S.M. Seroprevalence and risk factors associated whit Chlamydophila abortus infection in dairy goats in the Northeast of Brazil. Pesquisa Veterinária Brasileira, v.32, p.1082-1086, 2012. DOI: 10.1590/S0100-736X2012001100002.

SILVA, R.A.B.; BATISTA, M.C.S.; NASCIMENTO, C.B.; ALVES, R.P.A.; ALVES, F.S.F.; PINHEIRO, R.R.; SOUSA, M.S.; DINIZ, B.L.M.; CARDOSO, J.F.S.; PAULA, N.R.O. Caracterização zoosanitária da ovinocultura e da caprinocultura na microrregião homogênea de Teresina, Piauí, Brasil. Arquivos do Instituto Biológico, v.78, p.593-598, 2011.

STONE, D.M.; KUMTHEKAR, S.; CHIKWETO, A.; THOMAS, D.; TIWARI, K.; SHARMA, R.N. Exposure to zoonotic abortifacients among sheep and goats in Grenada. International Journal of Animal and Veterinary Advances, v.2, p.113-118, 2012.

TEANKUM, K.; POSPISCHIL, A.; JANETT, F.; BÜRGI, E.; BRUGNERA, E.; HOELZLE, K.; POLKINGHORNE, A.; WEILENMANN, R.; ZIMMERMANN, D.R.; BOREL, N. Detection of Chlamydiae in boar semen and genital tracts. Veterinary Microbiology, v.116, p.149-157, 2006. DOI: 10.1016/j. vetmic.2006.03.021.

WARETH, G.; MELZER, F.; TOMASO, H.; ROESLER, U.; NEUBAUER, H. Detection of Brucella abortus DNA in aborted goats and sheep in Egypt by real-time PCR. BMC Research Notes, v.8, p.212, 2015. DOI: 10.1186/s13104-015-1173-1.

Recebido em 27 de outubro de 2014 e aprovado em 10 de novembro de 2015

Pesq. agropec. bras., Brasília, v.51, n.5, p.654-660, maio 2016

DOI: $10.1590 / \mathrm{S} 0100-204 X 2016000500028$ 